\title{
Biyokütle Kaynaklı Sentez Gazından Hidrojen Üretimine Entegre Bir Güç Sisteminin Modellenmesi
}

\author{
Mehmet Selçuk MERT*iD, Fikret YÜKSEL, Mehmet Emre BURULDAY \\ Yalova Üniversitesi, Enerji Sistemleri Mühendisliği Bölümü, 77200, Yalova, Türkiye
}

Geliş / Received: 28/08/2018, Kabul / Accepted: 11/07/2019

\begin{abstract}
$\ddot{\mathbf{O z}}$
Ülkemizde bazı bölgelerde bulunan zengin jeotermal enerji kaynaklarının değerlendirilmesi, yerli ve yenilenebilir enerji üretimine imkân vermektedir. Aynı zamanda, bu bölgelerde önemli miktarlarda biyokütle atık potansiyellerinin bulunması, bir enerji taşıyıcısı olan hidrojen gazı üretimi için de kaynak oluşturmaktadır. Biyokütlenin gazlaştırılması sonucunda elde edilen sentez gazı kullanılarak yüksek saflıkta hidrojen üretimi yapılabilmektedir. $\mathrm{Bu}$ çalışma kapsamında, jeotermal ve biyokütle enerji kaynaklarının birlikte değerlendirilmesi hedeflenmiştir. Jeotermal kaynaklara sahip olan Manisa Alaşehir bölgesinde kurulabilecek biyokütle kaynaklı sentez gazından hidrojen üretimine entegre bir güç üretim sistemi modellenmiştir. Bunun için, sentez gazı debisi 3 kg/s olarak belirlenmiştir. Bu temelde, önerilen sistemin, Aspen HYSYS simülasyon programı kullanılarak benzetimi yapılmış ve sistemin yapılabilirliği araştırılmıştır. Benzetim ve analiz çalışmaları sonucunda, belirlenen kapasite için, hidrojen üretim sistemi ile birleşik tasarlanan bir organik Rankine çevrimi kullanılarak 729 kWe elektrik enerjisi üretilebilmektedir. Bu sayede, hidrojen üretim prosesinin tükettiği enerjinin bir kısmı karşılanabilmektedir. Bununla birlikte, ilave edilen jeotermal kaynaklı bir güç santrali ile de geri kalan enerji ihtiyacı sağlanabilmektedir. Önerilen sistemin kendi iç tüketimi toplamda 14.886 kWe'dir. Organik Rankine ve jeotermal kaynaklı güç çevrimlerinin toplam gücü ise $47.649 \mathrm{kWe}$ olarak bulunmuştur. Bu çalışmanın, biyokütle ve diğer yenilenebilir kaynakları içeren benzer hibrit sistemlerin ön tasarım çalışmalarına katkı sağlayabileceği değerlendirilmektedir.
\end{abstract}

Anahtar Kelimeler: Biyokütle, Hidrojen üretimi, Jeotermal Enerji, Simülasyon, Aspen HYSYS

Modeling of an Integrated Power System to Hydrogen Production from Biomass-Derived Synthesis Gas

\begin{abstract}
The assessment of the rich geothermal energy sources in some regions of our country enables domestic and renewable energy production. At the same time, the availability of significant biomass waste potentials in these regions is also a source of hydrogen gas production, an energy carrier. As a result of the gasification of the biomass, high purity hydrogen can be produced using the synthesis gas obtained. In this study, geothermal and biomass energy resources are aimed to be evaluated together. A power generation system integrated with hydrogen production from a biomass-derived synthesis gas, which can be installed in the Manisa Alaşehir region, which has geothermal resources, is modeled. For this, the synthesis gas content was determined to be 3 $\mathrm{kg} / \mathrm{s}$. On this basis, the proposed system is simulated using the Aspen HYSYS simulation software and the feasibility of the system is investigated. As a result of simulation and analysis studies, $729 \mathrm{kWe}$ of electric energy can be generated for an established capacity using an organic Rankine cycle designed with the hydrogen production system. Thus, some of the energy consumed by the hydrogen production process can be met. Furthermore, the remaining energy requirement can be achieved with the installed geothermal power plant. The proposed system has a total internal consumption of $14,886 \mathrm{kWe}$. The total power of Organic Rankine and geothermal power cycles is $47,649 \mathrm{kWe}$. It is assessed that this work may contribute to preliminary design studies of similar hybrid systems including biomass and other renewable resources.
\end{abstract}

Keywords: Biomass, Hydrogen Production, Geothermal Energy, Simulation, Aspen HYSYS 


\section{Giriş}

Sürdürülebilir enerji arz ve talep dengesinin sağlanması ekonomik kalkınmanın temel unsurlarındandır. $\mathrm{Bu}$ noktada, yerli ve yenilenebilir enerji kaynaklarının etkin ve verimli bir şekilde kullanılması, ülkemizin enerji güvenliğinin yanında ekonomik bağımsızlı̆̆ı açısından da önem taşımaktadır. Enerji ihtiyacının karşılanması amacıyla dışa bağımlı olarak temin edilen petrol, doğalgaz ve kömür gibi fosil yakıtların tüketiminin azaltılması, ülkemizde önemli potansiyele sahip güneş, rüzgâr, hidroelektrik, jeotermal ve biyokütle gibi yerli ve yenilenebilir enerji kaynakların kullanılması ile mümkün olabilir. Bununla birlikte, fosil yakıtların kullanılması sonucunda ortaya çıkan sera gazı emisyonları ve diğer çevresel etkileri, fosil enerji kaynaklarına alternatif temiz ve yüksek enerji içeriğine sahip bir yakıt ihtiyacını gündeme getirmektedir. Bu noktada, moleküler olarak doğada yaygın olarak bulunmamasına rağmen, farklı teknolojiler kullanılarak çeşitli kaynaklardan üretilebilen hidrojen gazı bir alternatif olarak öne çıkmaktadır. Biyokütle ve kömür kaynaklarının gazlaştırılması sonucu ortaya çıkan sentez gazından hidrojen gazı üretmek mümkündür. Gazlaştırma prosesi ile elde edilen sentez gazının bir takım proses işlemlerinden geçmesi ile temiz teknolojiler ile kullanılabilen ve katma değeri yüksek bir enerji taşıyıcısı olan hidrojen gazı üretilebilmektedir. Biyokütle dönüşüm teknolojileri arasında doğrudan yakma yerine, verimli ve daha temiz bir teknoloji olması sebebiyle gazlaştırma işlemi, biyoyakıt üretiminde tercih edilmektedir (Adamson, 2004).

Literatürde birleşik hidrojen ve güç üretim sistemleri üzerine yapılan çalışmalar genellikle biyokütle veya kömürün termokimyasal yöntemlerle dönüştürülmesi sonucu ortaya çıkan gaz ürünlerin doğrudan yakılması yada elde edilen sentez gazından ayrıştırılan hidrojenin bir yakma prosesinde değerlendirilmesi ile 1 s1 ve güç üretiminin gerçekleştirildiği entegre gazlaştırma kombine çevrim (IGCC) sistemlerini kapsamaktadır. Ayrıca, entegre yakıt hücreli tasarımlar ve elektroliz ile birlikte biyokütle tabanlı hidrojen üretim sistemleri ve yenilenebilir kaynaklı güç sistemlerinin birlikte değerlendirildiği modeller üzerine akademik çalışmalar mevcuttur. $\mathrm{Bu}$ çalışmalardan bazıları aşağıdaki gibi kısaca özetlenebilir. Salkuyeh (2015), çalışmasında yakıt olarak doğalgaz ve kaya gazı kullanarak çeşitli sıvı yakıtların üretimi ile birlikte güç üretiminin gerçekleştirildiği entegre sistem tasarlamıştır. Aspen Plus simülasyon programı kullanarak tasarladığı modellerin tekno-ekonomik analiz ve optimizasyonunu gerçekleştirmiştir. Çalışmada sonuç olarak, incelenen güç sisteminin piroliz ve gazlaştırma gibi termokimyasal yöntemler kullanılarak çeşitli sıvı veya gaz yakıt üretim sistemleri ile verimli bir şekilde entegre edilebileceği ve düşük $\mathrm{CO}_{2}$ emisyonlarının sağlanabileceği ortaya konulmuştur. Majoumerd (2014), $\mathrm{CO}_{2}$ yakalama metotları ile birlikte işletilebilecek hidrojence zengin sentez gazı üretimini incelemiş ve entegre gazlaştırma kombine çevrim (IGCC) uygulaması kapsamında gaz türbinli güç üretim sistemi modeli geliştirmiştir. Yapılan çalışma sonucunda, hidrojence zengin sentez gazının doğalgazlı sistemlere kıyasla gaz türbini uygulamalarında önemli değişikliklere gerek duyulmaksizın yakit olarak kullanılabileceği ve düşük $\mathrm{CO}_{2}$ emisyon değerlerinin sağlanabileceği belirtilmiştir Bir diğer çalışmada, Chen vd. (2012), Pro/II ${ }^{\circledR}$ V8.1.1 simülasyon programını kullanarak $\mathrm{CO}_{2}$ yakalama prosesine sahip bir entegre gazlaştırma kombine çevrim (IGCC) sisteminin performansını incelemiştir. Sistemde güç üretimi için gaz türbini, buhar türbini ve doğrudan sentez gazının iş gördüğü bir türbin sistemi kullanılarak \%42,22 verimle $311,78 \mathrm{MW}$ net elektrik çıkışı sağlanmış ve $\% 50$ ve \%90 oranlarında gerçekleşen $\mathrm{CO}_{2}$ yakalama sonucunda sistem veriminin sırasılyla $\% 38,96$ ve $\% 36,74$ 'e düştüğü 
hesaplanmıştır. Bhattacharya ve Dey (2014) 6,4 MWe entegre biyokütle gazlaştırma kombine çevrim (IBGCC) tesisinin teknik analizini yapmış ve sistem performansını incelemişlerdir. Sonuç olarak üç adet içten yanmalı gaz motoru kullanarak 5,85 MW elektrik enerjisi ve sistemin atık 1sisını kullanan bir Rankine çevrimi ile ilave $550 \mathrm{~kW}$ güç üretimi gerçekleştiren sistemin geleneksel yakma tesislerine kıyasla daha verimli ve avantajlı olduğu sonucuna ulaşmışlardır. Bai vd. (2017) enerji ihtiyacının yoğunlaştırılmış güneş enerjisi kullanılarak karşılandığı biyokütle kaynaklı gazlaştırmaya dayalı sentez gazı üretimine entegre gaz türbini ve Rankine çevrimli hibrit bir güç üretim sistemi tasarlamışlardır. Sistemin toplam enerji verimliliği \%27,93 olarak hesaplanırken güneş enerjisi kullanılarak elektrik üretim veriminin ise $\% 19,89$ 'a ulaştı̆̆ kaydedilmiştir. Perna vd. (2015) 100 kW kapasiteli kojenerasyon uygulaması kapsamında iki ayrı biyokütle gazlaştırma ve entegre katı oksit yakıt hücresi (SOFC) güç üretim sistemi modellemiştir. Modellenen gazlaştırma / SOFC entegre güç sisteminin termodinamik verimi \%30 olarak hesaplanmış ve geleneksel sistemlere kıyasla düşük emisyon değerlerine sahip olduğu ifade edilmiştir. Paengjuntuek vd. (2015) hammadde olarak pirinç samanı kullanan entegre bir biyokütle gazlaştırma yakıt hücresi (BGFC) sisteminin performansinı Aspen Plus simülasyon programını kullanarak incelemişlerdir. Çalışma sonucunda, optimum çalışma koşulları için 205,35 kg/saat pirinç samanının gazlaştırılmasıyla, buhar türbini ve SOFC kullanılarak 1395,61 kW net elektrik üretimi gerçekleştirilmiş ve sistemin toplam enerji verimi prosesteki atık buhar isısının da değerlendirilmesiyle $\quad \% 69,38 \quad$ olarak hesaplanmıştır. Nooruddin (2011) yakıt olarak linyit kömürü ve pamuk sapının kullanıldığı entegre gazlaştırma kombine çevrim (IGCC) uygulaması kapsamında hibrit bir güç ve hidrojen $\left(\mathrm{H}_{2}\right)$ üretim sisteminin simülasyon programı ile bilgisayar ortamında benzetimini yapmış ve optimizasyonunu gerçekleştirmiştir. Çalışmada, sisteme beslenecek optimum yakıt oranının pamuk sapları ve linyit kömürü için 40:60 olduğu, sadece kömür yerine biyokütle kömür karışımının yakıt olarak beslenmesi sonucunda gaz türbini çıkışındaki güç miktarında ve $\mathrm{H}_{2}$ üretiminde artış sağladığ 1 ortaya konulmuştur. Bununla birlikte, maksimum güç değerinde uygun $\mathrm{H}_{2}$ üretiminin sağlandığı gazlaştırma reaktörü çalışma sıcaklığı $1100-1130{ }^{\circ} \mathrm{C}$ aralığında bulunmuştur. Franzoni vd. (2009), buharlı bir güç üretim santrali ile entegre biyokütle ve kömür karışımlarının gazlaştırılmasıyla oluşan sentez gazına dayalı hidrojen üretim sistemi için termodinamik ve ekonomik model geliştirmiştir. Çalışma sonucunda elde edilen sonuçlara göre, gazlaştırmanın, sadece piroliz işlemine kıyasla buharlı enerji santralinin elektrik verimliliği üzerinde daha büyük bir etkiye sahip olduğu ve 200 MWth büyüklüğündeki bir gazlaştırma sisteminin entegrasyonunun, sistemden toplamda 2,5 puanlık bir verim kaybına sebep olduğu bulunmuştur. Ayrıca, gazlaştırma sürecinin, daha yüksek sermaye maliyetleri ve santraldeki verimlilik kaybından kaynaklanan gelir azalması nedeniyle daha maliyetli olduğu bu nedenle, piroliz sistemlerinin, elektrik ve hidrojen üretmek için cazip bir seçenek olarak değerlendirebileceği ancak piroliz teknolojisinin özellikle büyük boyutlu tesisler için geliştirilmesi gerekliliği vurgulanmıştır. Ersöz vd. (2018) tarafından lignoselülozik biyokütlenin gazlaştırılmasıyla elde edilen sentez gazından hidrojen üretimi incelenmiş ve biyokütlenin gazlaştırılarak yüksek saflıkta hidrojen üretimi sürecindeki adımlar Aspen HYSYS simülasyon programı kullanılarak modellenmiştir. Elde edilen bulgular temelinde, hidrojence zengin sentez gazı bileşimi belirlenmiş, basınç salınımlı adsorpsiyon (PSA) kullanılarak \%99.999 saflıkta $\mathrm{H}_{2}$ üretimi gerçekleştirilmiştir. PSA biriminden önce ürün gazının alt 1sıl değeri yaklaşık $4500 \mathrm{~kJ} / \mathrm{kg}$, soğuk gaz verimi ve 
toplam yakıt işleme verimleri ise sırasıyla, $\% 59$ ve $\% 93$ olarak bulunmuştur. Ayrıca beslenen $1 \mathrm{~kg}$ biyokütle için 76,1 g hidrojen üretiminin gerçekleştiği hesaplanmıştır.

$\mathrm{Bu}$ çalışmada, biyokütleden elde edilmiş sentez gazından, hidrojen gazı üretilmesi ve bu proses için gerekli olan enerjinin jeotermal enerji kaynaklı entegre bir güç üretim sisteminden karşılanması amacıyla simülasyon ve modelleme çalışması yapılarak, hidrojen ve güç üretiminin bir arada sağlandığı düşük $\mathrm{CO}_{2}$ emisyonlu hibrit bir sistemin yapılabilirliği araştırılmıştır.

\section{Materyal ve Metot}

\subsection{Biyokütle Kaynaklı Sentez Gazından Hidrojen Üretimi}

Biyokütle kaynaklı sentez gazından hidrojen üretim prosesi; biyokütle gazlaştırma, gaz temizleme, gaz şartlandırma ve hidrojen saflaştırma adımlarından meydana gelmektedir. Gazlaştırma teknolojisi, katı atıkların oksijen, buhar, hava veya bunların çeşitli karışımları ile reaksiyona girmesi sonucu sentez gazının oluşumu işlemidir. Üretilen sentez gazı, karbon monoksit (CO), hidrojen $\left(\mathrm{H}_{2}\right)$, metan $\left(\mathrm{CH}_{4}\right)$ ve karbondioksit $\left(\mathrm{CO}_{2}\right)$ gazlarının yanı sira hafif hidrokarbonlar ve katran gibi ağır hidrokarbonların bir karışımıdır (Yılmaz ve Selim, 2013). Gazlaştırma sonucu oluşan sentez gazında özellikle istenmeyen bileşim katrandır. Katran dönüşümü, genellikle soğuk ve sicak gaz temizleme sistemleri ile gerçekleştirilmektedir (Asadullah, 2014). Gaz şartlandırma adımında gerçekleşen su gaz kayma reaksiyonu (WGS), sentez gazındaki karbon monoksitin buhar ile tepkimeye girerek gaz içindeki hidrojenin zenginleştirilmesi için kullanılmaktadır. Beslenen su buharı vasitasiyla Denklem 1'e göre gerçekleşen reaksiyonda gazlaştırma sonrası oluşan sentez gazı içindeki CO miktarı azalırken, hidrojen ve $\mathrm{CO}_{2}$ miktarı artmaktadır. Su-gaz kayma reaksiyonları, katalizör içeren reaktörlerde gerçekleşmektedir (Bac vd., 2018).

$\mathrm{CO}(\mathrm{g})+\mathrm{H}_{2} \mathrm{O}(\mathrm{g}) \longleftrightarrow \mathrm{CO}_{2}(\mathrm{~g})+\mathrm{H}_{2}(\mathrm{~g})$

Gazlaştırma ile üretilen sentez gazı bileşimindeki hidrojenin saflaştırılması, Basınç Salınımlı Adsorpsiyon (PSA) ile mümkün olur. PSA teknolojisi, bir besleme gazı karışımının bir veya daha fazla bileşeninin bir katı adsorban üzerinde seçici olarak yüksek basınçta adsorpsiyonu ve gazların kısmi basınçlarından yararlanılarak nispeten düşük basınçta desorpsiyonu döngüsel işlemlerinden faydalanılarak istenilen gaz veya gazların karışım içerisindeki diğer bileşenlerden ayrıştırılması prensibine dayanmaktadır. PSA kullanımı ile hidrojen sentez gazı içerisindeki diğer bileşenlerden yüksek saflıkta ayrıştırılabilir (Sircar, 1989).

Tablo 1. Bölgesel biyokütle atık üretimi (Yenilenebilir Enerji Genel Müdürlüğü, Türkiye Biyokütle Enerjisi Potansiyeli Atlası (BEPA), son erişim tarihi: 10.06.2018)

\begin{tabular}{|l|r|r|r|}
\hline Bölge & $\begin{array}{r}\text { Tarla } \\
\text { Bitkileri } \\
\text { (ton/yl) }\end{array}$ & $\begin{array}{r}\text { Bahçe } \\
\text { Bitkileri } \\
\text { (ton/yll) }\end{array}$ & $\begin{array}{r}\text { Sebze } \\
\text { Bitkileri } \\
\text { (ton/yl) }\end{array}$ \\
\hline Manisa & 1687136,66 & 355088,82 & 545394,92 \\
\hline Uşak & 549210,00 & 19560,17 & 59752,04 \\
\hline İzmir & 3927773,10 & 149235,05 & 766984,47 \\
\hline Aydın & 2069021,28 & 154407,02 & 158685,58 \\
\hline Denizli & 1704173,80 & 196193,50 & 111556,01 \\
\hline Kütahya & 724589,24 & 6385,00 & 51180,98 \\
\hline Balıkesir & 3445329,48 & 80318,91 & 339972,12 \\
\hline Toplam & 14152233,56 & 961188,47 & 2033526,12 \\
\hline
\end{tabular}

Tablo 1'de Manisa ve yakın çevre illerindeki bitkisel atık miktarları görülmektedir.

Tablo 1 verilerine göre, tarla, bahçe ve sebze atıkları olmak üzere söz konusu bölgede toplamda y1llık $544 \mathrm{~kg} / \mathrm{s}$ debide bitkisel atık üretimi gerçekleşmektedir. Biyokütle atık potansiyeline bağlı olarak hidrojen üretiminde kullanılabilecek atıklar değerlendirildiğinde 3 $\mathrm{kg} / \mathrm{s}$ 'lik sentez gazı üretimi için bölgedeki 
biyokütle miktarının yeterli olduğu görülmektedir.

\subsection{Jeotermal kaynaklı güç sistemi}

Jeotermal kaynaklı sistemler, yanma prosesinin olmaması ve yakıt maliyetinin bulunmaması sebebiyle ilgi çekmektedir. Jeotermal enerji santralleri, jeotermal rezervuardan çıkarılan akışkanların 1s1 enerjisinden faydalanılarak, buhar türbinleri vasitasıyla mekanik enerji üretilmesine olanak sağlar. Jeotermal sahalarda kurulan sistemler ile çift fazlı jeotermal akışkanlar, ayırıcılar vasıtasıyla sıvı ve buhar fazlarına ayrıştırılır. Jeotermal su buharının taşıdığı enerji, sırasıyla mekanik ve elektrik enerjisine dönüştürülür. Ayırıcılardan elde edilen jeotermal sıvı ise içerisinde hala kullanılabilir enerji barındırdığından dolayı elektrik üretimi amacıyla bir organik Rankine çevriminin 1s1 kaynağı olarak kullanılabilir.

Organik Rankine çevrimi (ORC) düşük-orta ölçekli sıcaklık aralıklarında (100-170 ${ }^{\circ} \mathrm{C}$ arasında) çalışabilen ve organik bir çalışma akışkanın kullanıldığı güç çevrimidir. ORC çevrimi pompa, evaparatör, kondenser ve türbin-jeneratör ana ekipmanlarından meydana gelir. Jeotermal enerji kaynaklarının yanı sıra ORC'li sistemlerde endüstriyel atık 1S1, güneş ve biyokütle kaynaklı 1sı enerjisi de kullanılabilir (Desai ve Bandyopadhyay, 2009).

\subsection{Biyokütle sentez gazından hidrojen üretimi ve entegre güç sisteminin modellenmesi}

Biyokütle sentez gazından hidrojen ve entegre güç üretimi için önerilen hibrit sistemin bölgesel atık miktarları dikkate alınarak Manisa bölgesinde $165{ }^{\circ} \mathrm{C}$ sicaklık ve 661 $\mathrm{kg} / \mathrm{s}$ jeotermal akışkan değerlerine sahip jeotermal rezervuar olan bir saha üzerinde kurulması planlanmıştır. Sistemin blok akış diyagramı Şekil 1'de gösterilmiştir.

Sistem içerisinde sentez gazından hidrojen üretimi ve bu prosese entegre ORC-1 güç sistemi bulunmaktadir. Bununla birlikte, konvansiyonel Rankine ve organik Rankine (ORC-2) çevrimlerinden oluşan jeotermal kaynaklı güç sistemi de ilave edilmiştir. Önerilen hibrit sistemde hidrojen üretim prosesinin içerisinde yer alan ORC-1 ile hidrojen gazı üretimi için gerekli enerjinin bir kısmı karşılanabilirken, jeotermal kaynaklı sistemde bulunan konvansiyonel buhar türbini ve ORC-2 sistemi ile ihtiyaç duyulan enerjinin geri kanalı ve fazlası üretilebilmektedir. ORC1 hidrojen üretim sistemine sülfür giderim, WGS ve kompresör üniteleri çıkışlarındaki akımların sahip oldukları 1sıl enerjiden yararlanılarak entegre edilmiştir. Konvanisyonel Rankine çevrimi ve ORC-2'de ise jeotermal kaynak enerjisinden yararlanılmıştır. 

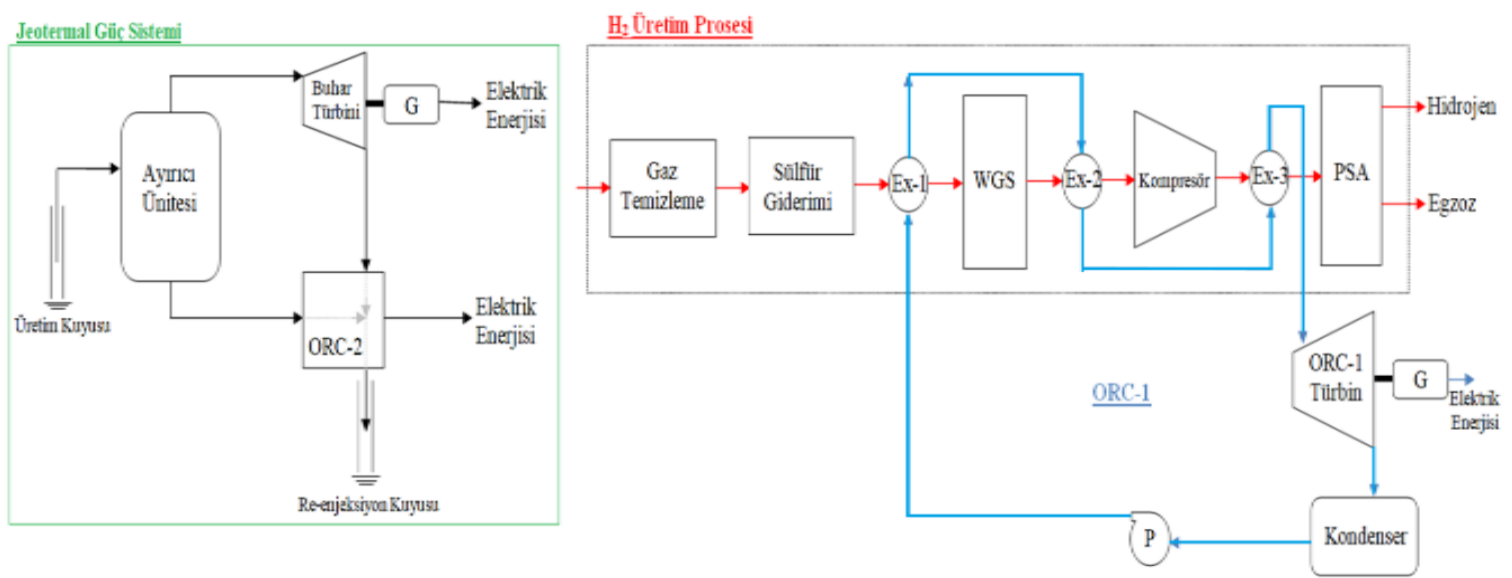

Şekil 1. Entegre hidrojen ve güç üretim sistemi

\section{Bulgular}

\subsection{Jeotermal Kaynaklı Güç Üretimi Simülasyon Sonuçları}

Aspen HYSYS simülasyon programı kullanılarak yapılan benzetim çalışmasının ekran görüntüsü Şekil 2'de gösterilmiştir. Buna göre, kuyudan alınan jeotermal akışkan ilk önce yüksek basınç (HP) ayırıcisına (V-100) gelmektedir. HP ayırıcıdan alınan kızgın su buharı yüksek basınç türbininde (K-101) genişletilerek 15,15 MW güç çıktısı elde edilmektedir. HP ayırıcıdan çıkan sıvı akımından düşük basınç (LP) ayırıcısı (V-101) kullanılarak elde edilen su buharı alçak basınç türbinine (K-102) gönderilerek genişletilmekte ve
19,34 MW güç çıktısı elde edilmektedir. LP ayırıcıdan (V-101) çıkan 3b numaralı sıv1 akımın sahip olduğu enerji, entegre edilen Organik Rankine Çevrimi (ORC-2) kullanılarak değerlendirilmekte ve sonrasında re-enjeksiyon pompası (P-101) kullanılarak jeotermal sıvı tekrar rezervuara basılarak rezervuarın sürdürülebilirliği korunmaktadır. Jeotermal sivinın basınçlandırılması ve rezervuara gönderilmesi amacıyla kullanılan pompa ise 4,07 MW güç tüketmektedir. HP buhar türbini (K-101) çıkışındaki 4 numaralı egzoz akımı ve LP ayırıcıdan (V-101) çıkan 3b numaralı sıv1 akımı, jeotermal destekli ORC sisteminin buharlaştırıcıları (E-100 ve E-101) kullanılarak ORC çalışma sıvısı olan R-134a organik akışkanına 1Sı kaynağ1 sağlamaktadır.

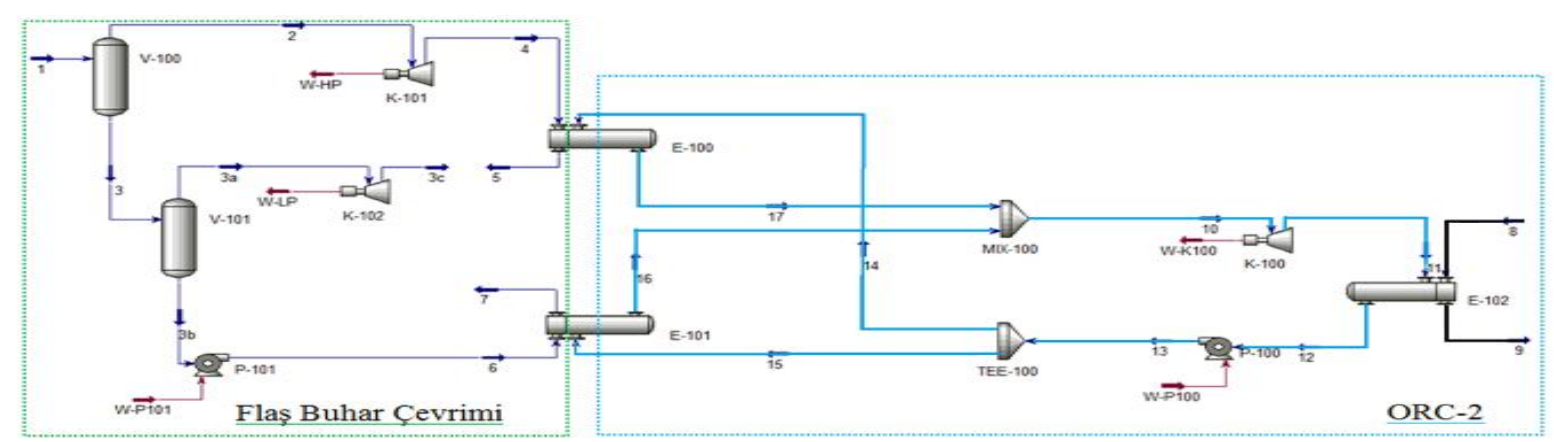

Şekil 2. Jeotermal kaynaklı güç üretim sistemi benzetim ekran görüntüsü

Şekil 2'de Aspen HYSYS ekran görüntüsü verilen sistemin benzetim çalışması 
sonucunda elde edilen proses akımlarına ait sıcaklık, basınç ve debi değerleri Tablo 2 'de verilmiştir. Benzetimi yapılan jeotermal güç santralindeki türbin ve pompalara ait enerji akımları ise Tablo 3'te, flaş buhar çevrimine ait T-s diyagramı Şekil 3'te gösterilmiştir.

Tablo 2. Jeotermal güç santrali benzetim çalışması akım bilgileri

\begin{tabular}{|l|r|r|r|r|r|r|r|r|r|r|}
\hline Akım No & $\mathbf{1}$ & $\mathbf{2}$ & $\mathbf{3}$ & $\mathbf{3 a}$ & $\mathbf{3 b}$ & $\mathbf{3 c}$ & $\mathbf{4}$ & $\mathbf{5}$ & $\mathbf{6}$ & $\mathbf{7}$ \\
\hline Sıcaklık $\left({ }^{\circ} \mathrm{C}\right)$ & 163,9 & 163,9 & 163,9 & 114,54 & 114,93 & 41,73 & 104,27 & 104,27 & 115,69 & 96,45 \\
\hline Basınç (bar) & 6,81 & 6,81 & 6,81 & 1,49 & 1,69 & 0,08 & 1,18 & 1,18 & 55 & 54,66 \\
\hline Debi $(\mathrm{kg} / \mathrm{s})$ & 661,1 & 66,1 & 595 & 59,1 & 535,9 & 59,1 & 66,1 & 66,1 & 535,9 & 535,9 \\
\hline Akım No & $\mathbf{8}$ & $\mathbf{9}$ & $\mathbf{1 0}$ & $\mathbf{1 1}$ & $\mathbf{1 2}$ & $\mathbf{1 3}$ & $\mathbf{1 4}$ & $\mathbf{1 5}$ & $\mathbf{1 6}$ & $\mathbf{1 7}$ \\
\hline Sicaklı $\left({ }^{\circ} \mathrm{C}\right)$ & 24,1 & 32,7 & 103,82 & 58,06 & 35,1 & 37,17 & 37,17 & 37,17 & 114,67 & 99 \\
\hline Basınç (bar) & 3,45 & 2,21 & 27,43 & 8,91 & 8,9 & 30,45 & 30,45 & 30,45 & 27,43 & 27,75 \\
\hline Debi $(\mathrm{kg} / \mathrm{s})$ & 3163,8 & 3163,8 & 598,5 & 598,5 & 598,5 & 598,5 & 398,8 & 199,7 & 199,7 & 398,8 \\
\hline
\end{tabular}

Tablo 3. Jeotermal güç santrali enerji akımları

\begin{tabular}{|l|r|r|r|r|r|r|r|}
\hline Enerji Akımı & W-P100 & W-P101 & W-K100 & W-HP & W-LP & Qüretim & QRe-enj \\
\hline Değer (MW) & 1,48 & 4,07 & 12,43 & 15,15 & 19,34 & 445 & 219 \\
\hline
\end{tabular}

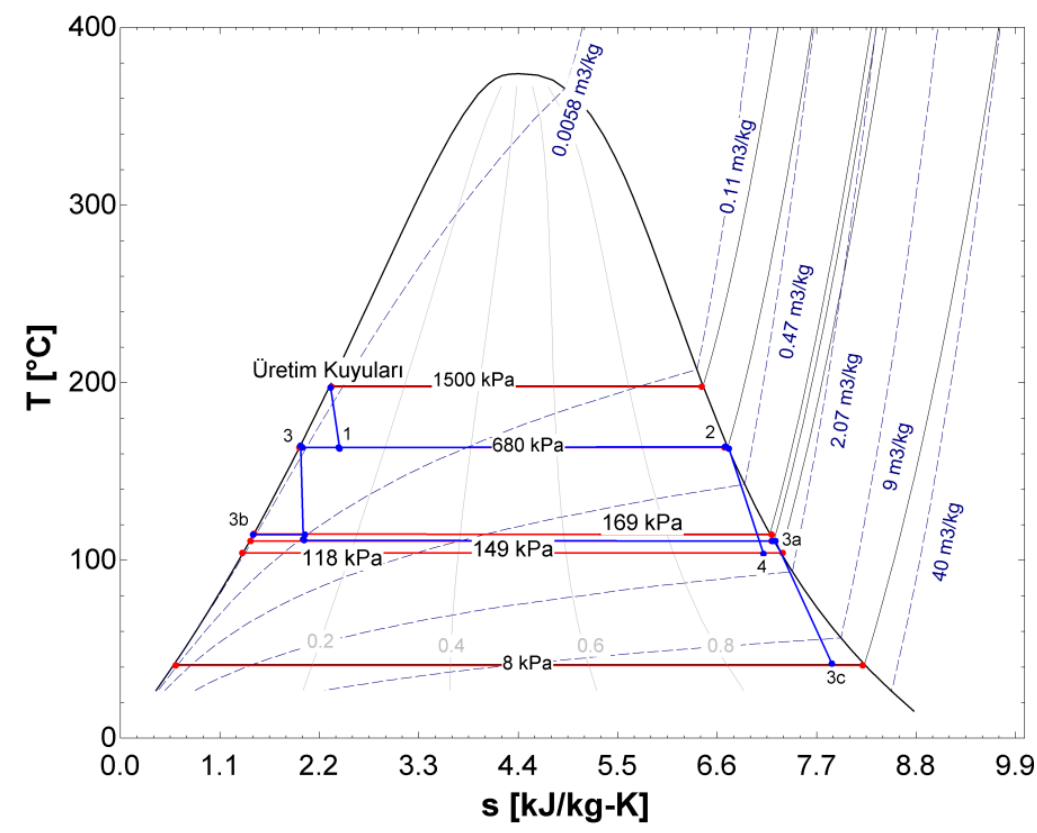

Şekil 3. Flaş buhar çevrimi T-s diyagramı

Buharlaştırıcılarda (E-100 ve E-101) jeotermal akışkandan ORC çalışma akışkanına 1sı transferi gerçekleştirilmesi ile elde edilen kızgın organik akışkanın ORC2 türbininde (K-100) genişletilmesi sonucunda 12,43 MW güç üretilmektedir. ORC türbinden çıkan 11 akım numaralı R134a çalışma akışkanının bir kondenser (E-
102) aracılığı ile soğutulduktan sonra tekrar basınçlandırılıp buharlaştırılmak üzere 1s1 değiştiricilerine gönderilmesi sonucunda kapalı çevrim tamamlanmaktadır. ORC çalışma akışkanının basınçlandırılması için kullanılan pompa (P-100) ise 1,48 MW güç tüketmektedir. Jeotermal güç üretim sisteminde kullanılan iki adet buhar türbini 
(K-101 ve K-102) ve bir adet ORC türbini (K-100) ile toplamda 46,92 MW güç üretilirken, jeotermal akışkanın rezervuara re-enjeksiyonu ve ORC çalışma akışkanının basınçlandırılması için kullanılan pompaların (P-101 ve P-100) tükettiği güç ise toplamda 5,55 MW değerindedir. ORC2 sistemine ait T-s diyagramı Şekil 4'te gösterilmiştir.

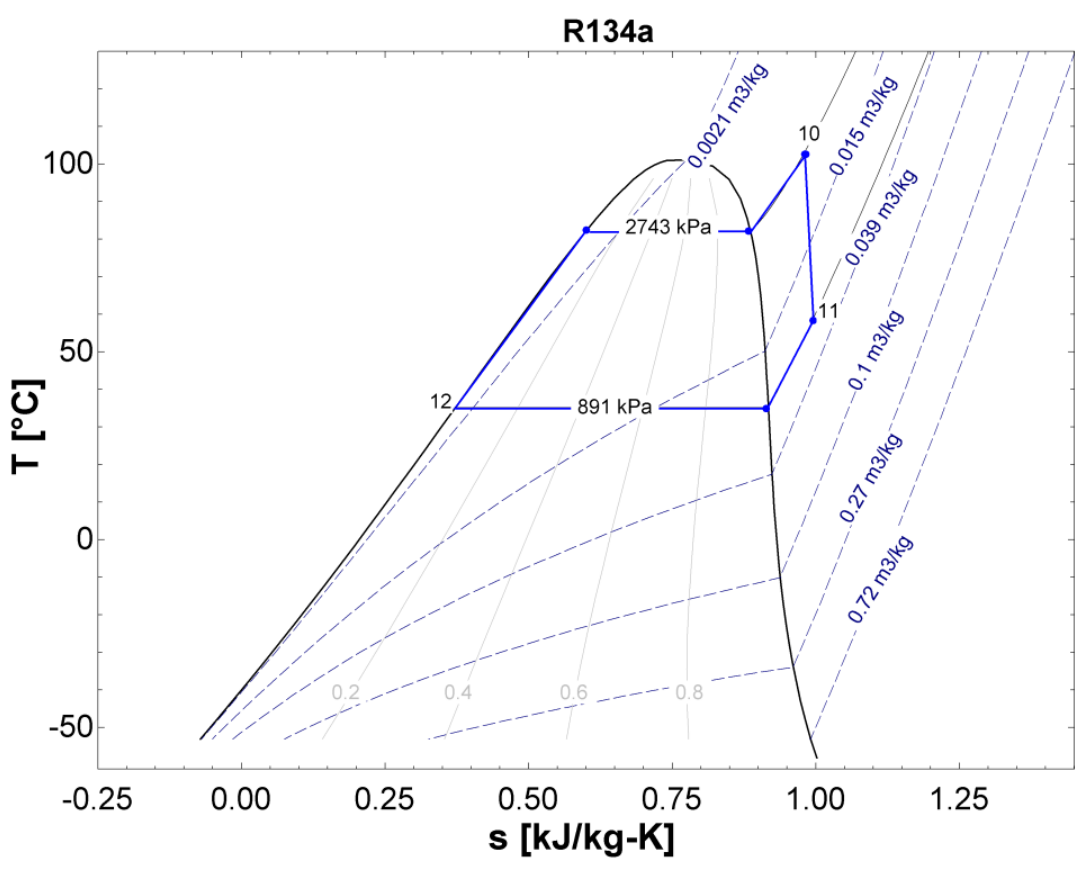

Şekil 4. Organik Rankine çevrimi (ORC-2) T-s diyagramı

Şekil 2'de benzetim ekran görüntüsü verilen organik Rankine çevrimi (ORC-2) ile entegre edilmiş jeotermal güç sistemine (1) numaralı akım vasitasiyla üretim kuyularından ulaşan çift fazlı jeotermal akışkan enerjisi (Qüretim) 445 MW'tır. Rezervuardan üretim kuyuları vasitasıyla sisteme beslenen jeotermal akışkan, enerjisinin belli bir miktarı kullanıldıktan sonra re-enjeksiyon kuyuları vasitasıyla tekrar rezervuara basılmaktadır. Rezervuara geri basılan akışkanın sahip olduğu enerji değeri ise (QRe-enj) 219 MW'tır. Bu durumda jeotermal destekli entegre güç sisteminde giren 1s1l enerji (Q Giren $) 226$ MW, net güç çıkışı ise 41,37 MW değerinde gerçekleşmektedir. Böylece sistemin enerji verimi $\% 18,3$ olarak hesaplanmıştır. Jeotermal akışkanın, belli bir sıcaklık değerinde ve yüksek miktarda kullanılmayan enerji ( $Q_{\text {Re-enj }}$ ) ile tekrar rezervuara basılması, nispeten düşük enerji verimine sebep olmasına karşın rezervuarın uzun ömürlü ve sürdürülebilir olabilmesi için önem taşımaktadır.

\subsection{Hidrojen Üretimi Simülasyon Sonuçları}

ORC entegre edilerek modellenen hidrojen üretim prosesinin benzetim ekran görüntüsü Şekil 5'te gösterilmiştir. Gazlaştırma ve katran giderimi sonrasinda elde edilen sentez gazı bir 1sı değiştiricisinden geçirilip, WGS reaktöründe hidrojence zenginleştirme işlemi için kullanılacak olan su akımının (S2) sicaklığını $836{ }^{\circ} \mathrm{C}^{\prime}$ ye çıkardıktan sonra $300{ }^{\circ} \mathrm{C}$ sicaklıkta sülfür giderim reaktörüne (X-1) gönderilmektedir. Sülfür giderimi sonrasinda WGS reaktöründe (ERV-1) hidrojen zenginleştirme işlemi için bölge biyokütle potansiyeline bağlı olarak öngörülen $3 \mathrm{~kg} / \mathrm{s}$ debi değerindeki sentez gazına beslemesi 
yapılmaktadır. Hidrojence zenginleştirme öncesi 5 numaralı akımda sentez gazı içerisindeki hidrojen miktarı $0,22 \mathrm{~kg} / \mathrm{s}$ iken, zenginleştirme sonrası 6 numaralı akımda hidrojen miktarı $0,31 \mathrm{~kg} / \mathrm{s}$ değerine çıkmaktadır. WGS reaktörü çalışma sicaklığı $200-400{ }^{\circ} \mathrm{C}$ aralığında olmaktadır. WGS reaktöründen (ERV-1) çıkan 6 numaralı akımın içerisinde bulunan suyun ayrışması için sentez gazı $4{ }^{\circ} \mathrm{C}$ sicaklığa kadar soğutularak bir ayırıcıya (V-1) gönderilmekte ve buradan 9 numaralı gaz akım 3,71 $\mathrm{kg} / \mathrm{s}$ debi değerinde ayrılmaktadır. Sentez gazı içerisindeki hidrojenin saflaştırılması için basınç salınımlı adsorpsiyon (PSA) reaktörü (X-2) kullanılmaktadır. Burada, gaz akımı yüksek bir basınç değerine getirilerek hidrojenin ayrıştırılması sağlanmaktadır. Gaz basıncının artırılması için kullanılan kompresörün (K-2) güç tüketimi 2.874 $\mathrm{kW}$ dır. PSA ünitesine giren 12 numaralı sentez gazı akımından $0,29 \mathrm{~kg} / \mathrm{s}$ debide hidrojen gazı ayrıştırılmaktadır.

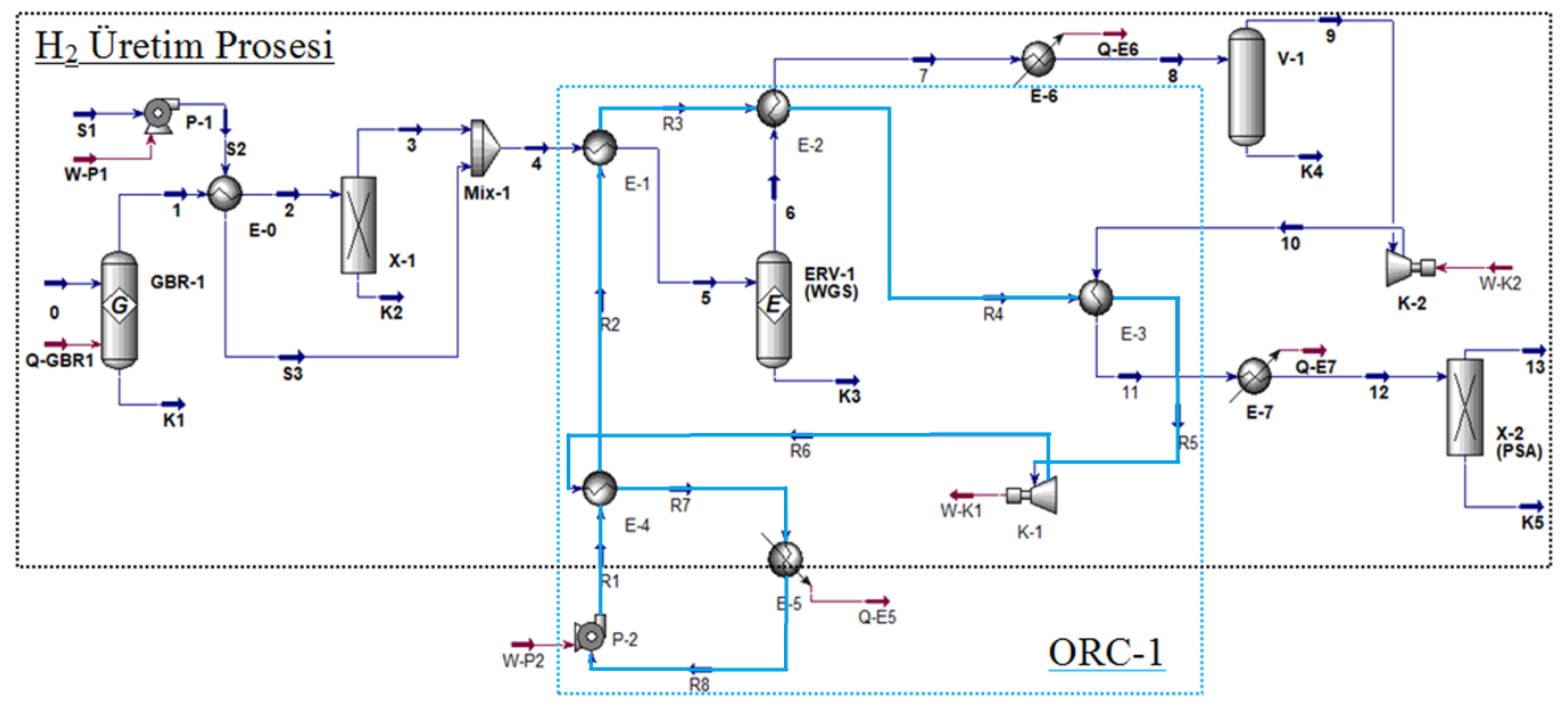

Şekil 5. ORC entegre edilerek modellenen hidrojen üretim sistemi benzetim ekran görüntüsü

$\mathrm{K} 5$ akımının temel içeriği ise $\mathrm{CO}, \mathrm{CO}_{2}$ ve az miktarda $\mathrm{CH}_{4}$ 'den oluşmaktadır. Sülfür giderimi, WGS reaktörü ve kompresör çıkış akımları sicaklıklarının sirasıyla $425{ }^{\circ} \mathrm{C}$, $400,6{ }^{\circ} \mathrm{C}$ ve $366,6^{\circ} \mathrm{C}$ olması sebebiyle üç adet 1 s1 değiştiricisi (E-1, E-2 ve E-3) kullanılarak hidrojen üretim prosesine bir Organik Rankine Çevrimi (ORC-1) entegre edilmiştir. Böylece entegre edilen ORC-1 sisteminde çalışma sıvısı olarak kullanılan $31 \mathrm{~kg} / \mathrm{s}$ debi değerindeki R-134a organik akışkanın sıcaklığı 3 kademeli olarak 113,4 ${ }^{\circ}$ C'ye çıkartılarak kızgın R-134a buharı elde edilmektedir. R134a'nın basınçlandırılması için kullanılan pompa (P-2) $71,5 \mathrm{~kW}$ güç tüketmektedir. ORC-1 sistemi ile $729 \mathrm{~kW}$ güç üretilebilmekte ve hidrojen üretim prosesinin ihtiyacının bir kısmı karşılanabilmektedir. Organik Rankine çevrimine (ORC-1) ait T-s diyagramı Şekil 6 'da gösterilmiştir. 


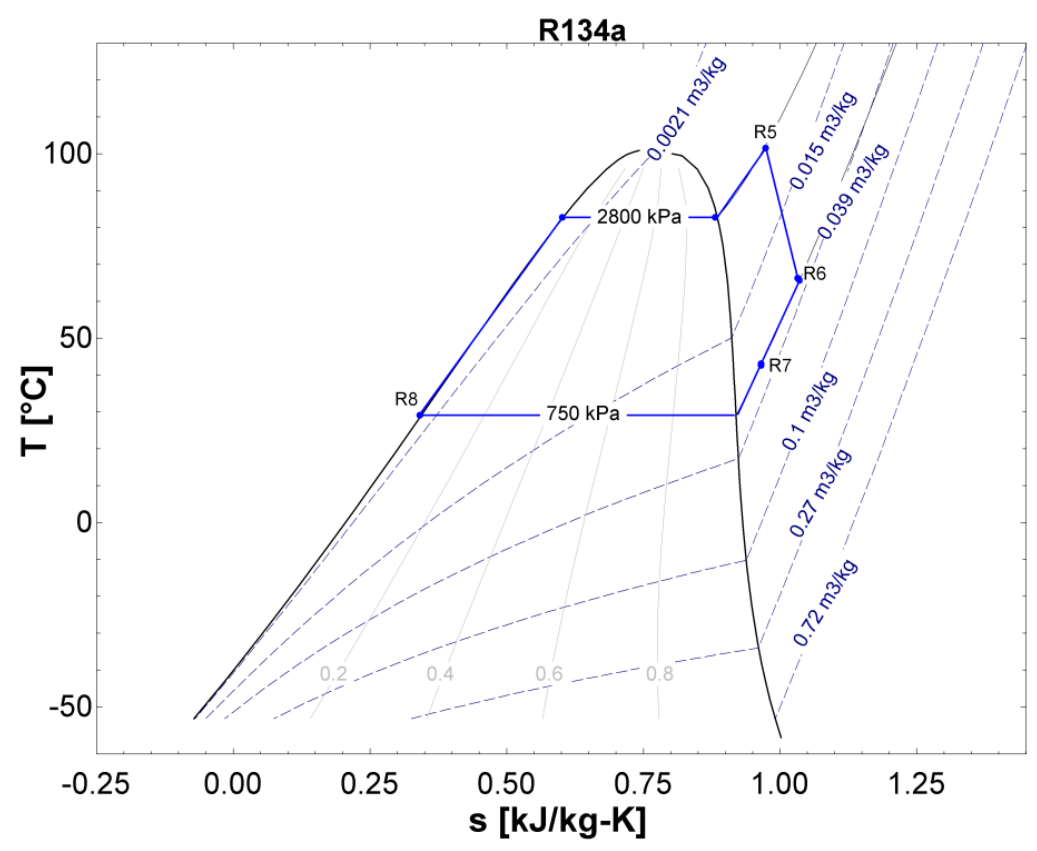

Şekil 6. Organik Rankine çevrimi (ORC-1) T-s diyagramı

Hidrojen üretim prosesinde kullanılan E1, E2 ve E3 1s1 değiştiricileri vasıtasıyla entegre edilen organik Rankine çevrimi (ORC-1) çalışma akışkanına toplamda $6.594 \mathrm{~kW}$ 1sı girişi olmuştur. ORC-1 sistemi ile $657,5 \mathrm{~kW}$ değerinde net güç üretilmiştir. $\mathrm{Bu}$ durumda hidrojen üretim prosesinde oluşan atık 1sıyı kaynak olarak kullanan ORC-1 sisteminin enerji verimi \%9,97 olarak hesaplanmıştır.

ORC entegre edilerek modellenen hidrojen üretim sistemi ekipmanlarının enerji akımları Tablo 4'te verilmiştir. PSA reaktörü öncesinde kullanılan bir adet kompresör ve ORC sisteminde çalışma akışkanının basınçlandırılması için kullanılan bir adet pompa nedeniyle hidrojen üretim prosesinde toplamda 2.946 kW elektriksel güç tüketimi meydana gelmektedir. Bununla birlikte, yapılan benzetim çalışması temelinde $3 \mathrm{~kg} / \mathrm{s}$ debi ve $850{ }^{\circ} \mathrm{C}$ sicaklıktaki sentez gazının eldesinde gazlaştırma ve gaz temizleme ünitelerinde yaklaşı olarak toplamda $6.391 \mathrm{~kW}$ enerji tüketimi olacağı öngörülmektedir. Bu değer biyokütlenin gazlaştırılması için kullanılan gazlaştırma reaktöründe $850{ }^{\circ} \mathrm{C}$ çalışma sıcaklığında ilgili miktardaki sentez gazının elde edilebilmesi, içerisinde bulunan katranın parçalanabilmesi ve giderilebilmesi için dışarıdan verilmesi gereken enerji miktarıdır. Burada göz önüne alınan bileşenler temel olarak reaktöre beslenen biyokütlenin ve gazlaştırıcı ajanın (hava/oksijen) miktarı, gazlaştırmanın gerçekleşmesi ve katran bileşiklerinin parçalanması için gerekli çalışma sıcaklığının sağlanması için gereken ısıtma enerjisidir.

Hidrojen üretim sisteminin Aspen HYSYS simülasyon programı ile benzetimi sonucunda elde edilen proses akımlarına ait sıcaklık, basınç ve debi değerleri Tablo 5 'te verilmiştir. 
Tablo 4. Hidrojen üretim prosesi enerji yükleri

\begin{tabular}{|l|c|c|c|c|}
\hline Enerji Akımı & $\boldsymbol{Q}$ - $\boldsymbol{E} 5$ & $\boldsymbol{Q}$-E7 & $\boldsymbol{W}$-K1 & $\boldsymbol{W}$-P1 \\
\hline Değer $(\boldsymbol{k W})$ & 1.053 & 451,47 & 729 & $1,169^{*} 10^{-2}$ \\
\hline Enerji Akımı & $\boldsymbol{Q}$ - $\boldsymbol{E} \boldsymbol{6}$ & $\boldsymbol{Q}$-GBRI & $\boldsymbol{W}-\boldsymbol{K} \mathbf{2}$ & $\boldsymbol{W}$-P2 \\
\hline Değer $(\boldsymbol{k W})$ & 1.052 & 455,51 & 2.874 & 71,50 \\
\hline Enerji Akımı & $\boldsymbol{E}-\mathbf{1}$ & $\boldsymbol{E}-\mathbf{2}$ & $\boldsymbol{E}-\mathbf{3}$ & \\
\hline Değer $(\boldsymbol{k W})$ & 1841 & 2669 & 2084 & \\
\hline
\end{tabular}

Tablo 5. Hidrojen üretim prosesine ait benzetim sonuçları

\begin{tabular}{|l|r|r|r|r|r|r|r|r|r|r|}
\hline Akım No & $\mathbf{0}$ & $\mathbf{1}$ & $\mathbf{2}$ & $\mathbf{3}$ & $\mathbf{4}$ & $\mathbf{5}$ & $\mathbf{6}$ & $\mathbf{7}$ & $\mathbf{8}$ & $\mathbf{9}$ \\
\hline Sıcaklık $\left({ }^{\circ} \mathrm{C}\right)$ & 750 & 850 & 300 & 300 & 425,57 & 200 & 400,6 & 82 & 4 & 4 \\
\hline Basınç (bar) & 1,2 & 1,2 & 1,1 & 1,1 & 1,1 & 1,1 & 1,05 & 1,05 & 0,9 & 0,9 \\
\hline Debi $(\mathrm{kg} / \mathrm{s})$ & 3 & 3 & 3 & 2,995 & 3,88 & 3,88 & 3,88 & 3,88 & 3,88 & 3,71 \\
\hline Akım No & $\mathbf{1 0}$ & $\mathbf{1 1}$ & $\mathbf{1 2}$ & $\mathbf{1 3}$ & $\mathbf{R 1}$ & $\mathbf{R 2}$ & $\mathbf{R 3}$ & $\mathbf{R 4}$ & $\mathbf{R 5}$ & $\mathbf{R 6}$ \\
\hline Sicaklık $\left({ }^{\circ} \mathrm{C}\right)$ & 366,6 & 108 & 50 & 54,8 & 30,95 & 45 & 77,57 & 82,61 & 113,4 & 66,23 \\
\hline Basınç (bar) & 12 & 12 & 11,9 & 11,9 & 28 & 28 & 28 & 28 & 28 & 7,5 \\
\hline Debi $(\mathrm{kg} / \mathrm{s})$ & 3,71 & 3,71 & 3,71 & 0,29 & 31 & 31 & 31 & 31 & 31 & 31 \\
\hline Akım No & $\mathbf{R 7}$ & $\mathbf{R 8}$ & $\mathbf{S 1}$ & $\mathbf{S 2}$ & $\mathbf{S 3}$ & $\mathbf{K 1}$ & $\mathbf{K 2}$ & $\mathbf{K 3}$ & $\mathbf{K 4}$ & $\mathbf{K} \mathbf{2}$ \\
\hline Sicaklık $\left({ }^{\circ} \mathrm{C}\right)$ & 43,76 & 29,13 & 25 & 25 & 836 & 850 & 300 & 400,6 & 4 & 54,84 \\
\hline Basıç (bar) & 7,5 & 7,5 & 1 & 1,1 & 1,1 & 1,2 & 1,1 & 1,05 & 0,9 & 11,9 \\
\hline Debi $(\mathrm{kg} / \mathrm{s})$ & 31 & 31 & 0,88 & 0,88 & 0,88 & 0 & 0,005 & 0 & 0,17 & 3,41 \\
\hline
\end{tabular}

\section{Sonuç ve Tartışma}

Biyokütle kaynaklı sentez gazından hidrojen üretimine entegre bir güç sisteminin yapılabilirliği araştırılmıştır. $\mathrm{Bu}$ kapsamda, Aspen HYSYS simülasyon programından yararlanılarak biyokütle sentez gazından yüksek saflıkta hidrojen gazı üretimi için benzetim çalışması yapılmıştır. Belirlenen kapasite için, sentez gazından yola çıkılarak hidrojen gazı eldesinde bir takim prosesler ve bu proseslerin gerçekleşmesi için de 9.337 $\mathrm{kWe}$ güç tüketimi gerekmektedir. $\mathrm{Bu}$ noktada, hidrojen üretim prosesinin ihtiyacını karşılamak üzere düşük sıcaklık 1S1 enerjisinden faydalanan bir organik Rankine çevrimi (ORC-1) hidrojen üretim prosesine entegre edilmiştir. Entegre edilen ORC-1 sisteminden $729 \mathrm{kWe}$ güç üretimi sağlanmıştır. Bununla birlikte, konvansiyonel ve organik Rankine çevrimlerini içeren jeotermal kaynaklı bir güç üretim sistemi entegrasyonu da yapılmıştır.
Jeotermal kaynaklı sistemin iç tüketimi $5.550 \mathrm{kWe}$ olmaktadır. Tüm prosesin toplam iç tüketimi ise $14.886 \mathrm{kWe}$ 'dir. Buna karş1lı, önerilen entegre prosesin toplam güç üretim miktarı $47.649 \mathrm{kWe}$ 'dir. Toplam net güç üretimi ise $32.763 \mathrm{kWe}$ olarak bulunmuştur. Bunun yanında, 1.055 $\mathrm{kg} /$ saat'lik bir debide hidrojen gazı üretimi gerçekleştirilmiştir. Yıllık 7.200 saatlik çalışma süresi temelinde hidrojen gazı üretim miktarı 7.596 ton/yıl olarak hesaplanmıştır. Buna ilaveten, bölgenin biyokütle potansiyeline bağlı olarak tesisin hidrojen üretim kapasitesinin artırılabileceği öngörülmektedir.

Sonuç olarak, jeotermal ve biyokütle gibi yerli ve yenilenebilir enerji kaynaklarının etkin ve verimli bir şekilde kullanılması, enerji güvenliğinin sağlanması bakımından önem arz etmektedir. $\mathrm{Bu}$ çalışma kapsamında benzetimi ve modellemesi yapılmış olan entegre sistemin ve benzer sistemlerin geliştirilmesinin, ülkemizin enerjide olan dışa bağımlılığının 
azaltılmasında $\quad$ katk1 sağlayacağ değerlendirilmektedir.

\section{Teşekkür}

$\mathrm{Bu}$ çalışma, TÜBİTAK-1003 Öncelikli Alanlar Ar-Ge Projeleri Destekleme Programı kapsaminda TÜBİTAK tarafindan desteklenen "Biyokütleden Gazlaştırma Yoluyla Hidrojen Üretim Teknolojisi" başliklı proje (Proje no: 213M368) kapsamında yapılmıştır. Desteklerinden dolayı TÜBİTAK'a ve proje ekibine teşekkür ederiz. Ayrıca, bu çalışmanın gerçekleştirilmesinde yüksek lisans tez projesi desteği sağlayan Yalova Üniversitesi Bilimsel Araştırma Projeleri Koordinasyon Birimi'ne (Proje No: 2018/YL/009) teşekkür ederiz.

\section{Semboller}

ERV :Denge Reaktörü (Equilibrium Reactor Vessel)

Ex : Isı Değiştiricisi (Exchanger)

HP : Yüksek Basınç (High Pressure)

G : Jeneratör (Generator)

GBR : Gibbs Reaktörü (Gibbs Reactor)

LP : Alçak Basınç (Low Pressure)

ORC : Organik Rankine Çevrimi (Organic Rankine Cycle)

P : Pompa (Pump)

PSA :Basınç Salınımlı Adsorpsiyon (Pressure Swing Adsorption)

WGS : Su-Gaz Dönüşümü (Water Gas Shift)

\section{Kaynaklar}

Adamson, K. 2004. "Hydrogen from renewable-the hundred year commitment", Energy Policy, 32, 1231-1242.

Asadullah M. 2014. "Biomass gasification gas cleaning for downstream applications: A comparative critical review", Renewable and Sustainable Energy Reviews 40, 118132.

Bac, S., Keskin, S., Avci, A. 2018. "Modeling and simulation of water-gas shift in a heat exchange integrated microchannel converter", International Journal of Hydrogen Energy, 43, 10941104.

Bai, Z., Liu, Q., Lei, J., Hong, H., Jin, H. 2017. "New solar-biomass power generation system integrated a two-stage gasifier", Applied Energy, 194, 310-319.

Bhattacharya, P. and Dey, S. 2014. "An Update Technology for Integrated Biomass Gasification Combined Cycle Power Plant", Applied Solar Energy, 50(1), 44-48.

Ersoz, A., Çetin Durak, Y., Sarığlan, A., Turan, A.Z., Mert, M.S., Yüksel, F., Figen, H.E., Güldal, N.O., Karaismailoglu, M., Baykara, S.Z. 2018. "Investigation of a novel \& integrated simulation model for hydrogen production from lignocellulosic biomass." International Journal of Hydrogen Energy, 43(2),1081-1093.

Franzoni, A., Galanti, L., Traverso, A., Massardo, A.F. 2009. "Integrated Systems for Electricity and Hydrogen Co-production from Coal and Biomass", International Journal of Thermodynamics, 12 (2), 97104.

Desai, N.B., Bandyopadhyay, S. 2009. "Process integration of organic Rankine cycle", Energy 34 1674-1686.

Majoumerd, M.M. , De, S., Assadi, M., Breuhaus, P. 2012. "An EU initiative for future generation of IGCC power plants using hydrogen-rich syngas: Simulation results for the baseline configuration", Applied Energy, 99, 280-290.

Nooruddin, O. 2011. "Simulation and Optimization of IGCC Technique for Power Generation and Hydrogen Production by Using Lignite Thar Coal and Cotton Stalk", Yüksek Lisans Tezi, Lappeenranta University of Technology Faculty of Technology Master's Degree Programme in Chemical and Process Engineering, Lappeenranta, 69-72. 
Chen, P.C., Chiu, H.M., Chyou, Y.P. 2012.

"Process analysis study of integrated gasification combinedcycle with $\mathrm{CO} 2$ capture", Procedia Engineering, 42, 1502 -1513 .

Pernaa, A., Minutillob, M., Cicconardia, S.P., Jannellib, E., Scarfoglierob, S. 2015. "Conventional and advanced biomass gasification power plants designed for cogeneration purpose", Energy Procedia $82,687-694$.

Paengjuntueka, W., Boonmaka, J., Mungkalasirib, J. 2015. "Energy Efficiency Analysis in An Integrated Biomass Gasification Fuel Cell System", Energy Procedia 79, 430-435.

Salkuyeh, Y.K., Elkamel, A., The, J., Fowler, M. 2016. "Development and techno-economic analysis of an integrated petroleum coke, biomass, and natural gas polygeneration process", Energy, 113, 861874.

Sircar S. (1989) "Pressure Swing Adsorption Technology", In: Rodrigues A.E., LeVan M.D., Tondeur D. (eds) Adsorption: Science and Technology. NATO ASI Series (Series E: Applied Sciences), vol 158. Springer, Dordrecht, 285-321.

Y1lmaz S. ve Selim H., 2013. "A review on the methods for biomass to energy conversion systems design", Renewable Sustainable Energy Rev, 25, 420-30.

Yenilenebilir Enerji Genel Müdürlüğü. "Türkiye biyokütle enerjisi potansiyeli atlas1 (BEPA)", http://bepa.yegm.gov.tr/ Son erişim tarihi: 10.06 .2018 